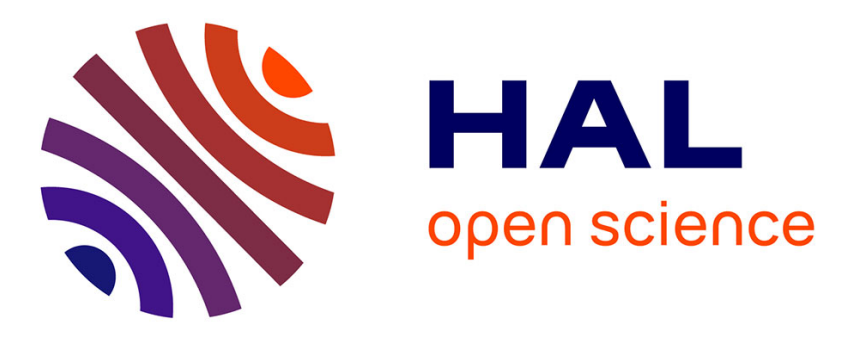

\title{
Electrochemical Skin Conductance and Quantitative Sensory Testing on Fibromyalgia
}

\author{
Gisèle Pickering, Alexanne Achard, Alexandrine Corriger, Sophia \\ Sickout-arondo, Nicolas Macian, Vincent Leray, Camille Lucchini, Jean-Michel \\ Cardot, Bruno Pereira
}

\section{To cite this version:}

Gisèle Pickering, Alexanne Achard, Alexandrine Corriger, Sophia Sickout-arondo, Nicolas Macian, et al.. Electrochemical Skin Conductance and Quantitative Sensory Testing on Fibromyalgia. Pain Practice, 2020, 20 (4), pp.348-356. 10.1111/papr.12857 . hal-02935679

\section{HAL Id: hal-02935679 \\ https://hal.inrae.fr/hal-02935679}

Submitted on 10 Sep 2020

HAL is a multi-disciplinary open access archive for the deposit and dissemination of scientific research documents, whether they are published or not. The documents may come from teaching and research institutions in France or abroad, or from public or private research centers.
L'archive ouverte pluridisciplinaire HAL, est destinée au dépôt et à la diffusion de documents scientifiques de niveau recherche, publiés ou non, émanant des établissements d'enseignement et de recherche français ou étrangers, des laboratoires publics ou privés.

\section{(c)(1)}

Distributed under a Creative Commons Attribution| 4.0 International License 


\title{
ORIGINAL ARTICLE
}

\section{Electrochemical Skin Conductance and Quantitative Sensory Testing on Fibromyalgia}

\author{
Gisèle Pickering (D, MD, PhD, DPharm**, ${ }^{*}$ Alexanne Achard, DPharm ${ }^{\dagger}$; \\ Alexandrine Corriger, $\mathrm{PhD}^{*}{ }^{\dagger}$; Sophia Sickout-Arondo, $\mathrm{MSc}^{\dagger}$; Nicolas Macian, \\ $\mathrm{MSc}^{\dagger}$; Vincent Leray, $\mathrm{MSc}^{\dagger}$; Camille Lucchini, $\mathrm{MSc}^{\dagger}$; Jean-Michel Cardot, PhD, \\ DPharm $^{\ddagger}$; Bruno Pereira, $\mathrm{PhD}^{\mathbb{S}}$ \\ *Neuro-Dol Laboratory Inserm 1107, Clermont Auvergne University, Clermont-Ferrand, \\ France; ${ }^{\dagger}$ Clinical Pharmacology Department, CPC/CIC Inserm 1405, Clermont-Ferrand \\ University Hospital, Clermont-Ferrand, France; ${ }^{\ddagger}$ CIC Inserm 1405, Clermont-Ferrand \\ University Hospital, Clermont Auvergne University MEDIS, Clermont-Ferrand, France; \\ ${ }^{\$}$ Biostatistics Unit (DRCI), Clermont-Ferrand University Hospital, Clermont-Ferrand, France
}

\section{Abstract}

Background: An impairment of the peripheral nervous system has been suggested in fibromyalgia (FM). Noninvasive distal electrochemical skin conductance (ESC) has been studied little so far when combined with quantitative sensory testing (QST) in patients with FM.

Methods: This study (clinicaltrials.gov NCT03347669) included 50 female patients with FM and 50 matched healthy volunteers (HVs). ESC (measured in microsiemens [ $\mu \mathrm{S}$ ] with Sudoscan), as well as psychological, quality of life, sleep, and social characteristics, were assessed in both groups. In a subgroup of 24 patients with FM and 24 HVs, QST of cold and warm detection and pain thresholds and diffuse noxious inhibitory controls (DNICs) were explored. Statistical analysis was performed for a 2-sided type I error at $5 \%$.

Address correspondence and reprint request to: Gisèle Pickering, $M D$ PhD, DPharm, Clinical Pharmacology Department, CPC/CIC Inserm 1405, University Hospital CHU, F-63001 Clermont-Ferrand, France. E-mail: gisele.pickering@uca.fr.

Clinical Trial Registration: NCT03347669

Submitted: June 20, 2019; Revised: October 22, 2019;

Revision accepted: November 5, 2019

DOI. 10.1111/papr.12857

(c) 2019 World Institute of Pain, 1530-7085/18/\$15.00

Pain Practice, Volume 20, Issue 4, 2020 348-356

Results: Between patients with FM and HVs, ESC values differed $(71.4 \pm 11.2 \mu \mathrm{S}$ vs. $74.4 \pm 10.3 \mu \mathrm{S}$, respectively; $P=0.003)$, especially on the dominant hand $(P=0.03)$, where more patients with FM had ESC values $<66 \mu \mathrm{S}$ than did HVs $(P=0.046)$. No difference was observed on feet. In patients with FM, all collected characteristics were impaired $(P<0.001)$, DNICs were less functional, detection thresholds occurred later, and pain thresholds occurred earlier. No correlation was observed between ESC and DNICs or with any parameter.

Conclusion: This study shows that the sudomotor function is significantly impaired in patients with FM, especially on the dominant hand. This occurs in parallel with adjustments of detection and pain thresholds in the context of deficient spinal pain modulation. ESC values combined with QST values are relevant in the context of patients with FM and need to be explored further in this nociception-autonomic system intertwining.

Key Words: fibromyalgia, small nerve fibers, neuropathy, sweat glands, Sudoscan

\section{INTRODUCTION}


fatigue, and sleep, psychological, and digestive disorders. $^{2}$ Clinical and quantitative sensory testing (QST) studies have shown that modulation of pain in FM is impaired and pain thresholds diminished. ${ }^{3,4}$ Among factors that have been suggested for the pathophysiology of FM, in a high percentage of patients, an impairment of the peripheral nervous system with small nerve fiber alteration, small fiber neuropathy (SFN), ${ }^{5,6}$ and dysautonomia has been described. SFN is a generic term for a selective or predominant impairment of peripheral afferent thinly myelinated (A-delta) and unmyelinated (C) nerve fibers. However, its diagnosis and features pose a number of difficulties, including changes in the course of neuropathy over time, poor knowledge of nonsymmetric length-dependent SFN, and occurrence in conditions precisely like FM that do not match the definition of peripheral neuropathy. ${ }^{7}$ SFN and FM symptoms do intertwine, since SFN also includes allodynia, hyperesthesia, paresthesia, severe fatigue, concentration disorders, burning, and pain sensation. ${ }^{8,9}$ Another complexity arises from dysautonomia that has been described in FM, but autonomic features do not always parallel the somatic features of the neuropathy, ${ }^{10}$ and the degree of dysautonomia may vary in patients with $\mathrm{FM}^{11}$ Autonomic dysfunction could even be the common clustering of FM, chronic fatigue syndrome, irritable bowel syndrome, and interstitial cystitis, and underlie their pathogenesis. ${ }^{12} \mathrm{~A}-$ delta and $\mathrm{C}$ nerve fibers, involved in painful and thermal perception, also innervate sweat glands that are linked to the autonomic nervous system, ${ }^{13-16}$ and sweat gland innervation could be dysfunctional because of an alteration of these nerve fibers. Such a dysautonomia may be a detectable abnormality in diabetic SFN, ${ }^{17}$ familial amyloid polyneuropathy, or Fabry's disease, ${ }^{15,18-22}$ and has been studied using an electrophysiological noninvasive tool (Sudoscan; Impeto Medical, Paris, France) that measures electrochemical skin conductance (ESC).

The present study aims to explore ESC measurement using Sudoscan in patients with FM compared to matched healthy volunteers (HVs) and QST studies, with the hypothesis of a possible correlation between them and the presence of sweat gland dysfunction/ dysautonomia in patients with FM.

\section{METHODS}

\section{Study Design}

This study is a pilot single-site clinical study that included 50 female patients with FM and 50 HVs. It was carried out in the Clinical Pharmacology Centre/ CIC Inserm-1405, University Hospital, Clermont-Ferrand, France, according to good clinical practice. The French Research Ethics Committee gave its approval on October 5, 2017 (ethics committee number IORG_404310/reference 2017-47-2); this trial is registered in ClinicalTrials.gov (trial number NCT03347669). The study took place from November 2017 to September 2018.

\section{Study Population}

Patients with FM were included in this study if they fulfilled the following criteria: were 18 to 65 years old, met American College of Rheumatology (ACR) 2016 diagnostic criteria, and gave written informed consent. Every patient with FM was matched for age, gender, body mass index (BMI), and menopausal status with an HV, who was concomitantly included. Exclusion criteria were common to both groups and included incompatible medical or/and surgery history, carpal tunnel syndrome, an inability to put hands and feet on Sudoscan electrodes, breastfeeding women, and childbearing women.

\section{Objectives}

The primary objective was to compare the sweat gland function in patients with FM and HVs. The secondary objectives aimed to compare psychological, quality of life, sleep, and social criteria.

\section{Endpoints}

Primary Endpoint. The primary endpoint was the difference of ESC values, in patients with FM and HVs, on hands and feet measured by Sudoscan, a noninvasive, quantitative, rapid, and reproducible tool that evaluates sweat gland function. ${ }^{18,19,22,23}$ This device is based on an electrochemical reaction between steel electrodes and chloride ions. ${ }^{19}$ Sudoscan measurements were carried out twice, at $T_{0}$ and $T_{0}+30 \mathrm{~min}-$ utes $\left(T_{30}\right)$, to ensure reproducibility of the test.

Secondary Endpoints. FM diagnosis and pain status FM diagnosis was evaluated using the ACR 2016 criteria $^{24}$ the Fibromyalgia Impact Questionnaire (FIQ; average $\mathrm{FM}>50$, severe $\mathrm{FM}>70$ ), ${ }^{25}$ and the Fibromyalgia Rapid Screening Tool (FIRST; a patient suffering from FM has a FIRST score $\geq 5) .{ }^{26}$ Pain was 
assessed using a numerical pain rating scale (NPRS) ranging from 0 to $10(0=$ no pain and $10=$ the worst pain possible) and the Brief Pain Inventory (BPI), ${ }^{27}$ a questionnaire composed of 9 items that characterize pain compared to its intensity and psychosocial repercussions. The patient rates each question on a scale from 0 to 10 . For one question, the patient has to mark the painful areas on a body diagram.

Questionnaires - Quality of life was assessed using the 12-Item Short Form Survey (SF-12), ${ }^{28}$ a multipurpose short form survey with 12 questions. It was developed to provide a shorter, yet valid, alternative to the SF-36. ${ }^{29}$ Anxiety and depression were assessed using the Hospital Anxiety and Depression Scale (HADS) ${ }^{30}$ and the Beck Depression Inventory (BDI). ${ }^{31}$ The HADS is a validated self-questionnaire composed of 14 items completed by the patient, divided into 2 subscales: 7 of the items relate to anxiety and 7 relate to depression. Each item is rated from 0 to 3 , for a total possible score of 21 on each subscale. Four anxiety/depression classes have been defined: 0 to $7=$ normal, 8 to $10=$ moderate, 11 to 21 = severe. The BDI, a validated self-questionnaire, is composed of 13 items. Each item consists of 4 sentences corresponding to 4 degrees of increasing intensity of a symptom, scored from 0 to 3 . The global score is obtained by adding the scores of the 13 items. The score may vary from 0 to 39 . Four classes have been defined: 0 to $4=$ no depression; 4 to $7=$ slight depression; 8 to $15=$ moderate depression; and 16 and more $=$ severe depression.

Quality of sleep was assessed using the Pittsburgh Sleep Quality Index (PSQI). ${ }^{32}$ It is a questionnaire composed of 19 items assessing 7 domains: subjective sleep quality, sleep latency, sleep duration, habitual sleep efficiency, sleep disturbances, use of sleep medication, and daytime dysfunction. Each domain is scored from 0 to 3 . The global score is a sum of the 7 domains and varies from 0 to 21 . Severity of fatigue was evaluated using the Fatigue Severity Scale (FSS), ${ }^{33}$ a 9. item self-questionnaire to identify fatigue intensity. Each score varies from 1 to 7 for each question, a low value representing a low intensity.

Catastrophizing was assessed using the Pain Catastrophizing Scale (PCS), ${ }^{34}$ a 13 -item questionnaire allowing the patient to describe thoughts and emotions during pain. The patient indicates to what extent she has these thoughts or emotions when she feels pain by assigning a score between 0 (not at all) and 4 (all the time) to each item. The final score is the sum of the scores for each question. Social vulnerability is assessed by a French questionnaire, Evaluation de la Précarité et des Inégalités de Santé dans les Centres d'Examens de Santé (EPICES). ${ }^{35}$ This questionnaire is composed of 11 binary questions indicating precariousness and health inequalities, which are scored from 0 to 100 . A patient is socially vulnerable if the EPICES score $\geq 30.2$.

Psychophysics testing - Twenty-four of 50 patients with FM and $24 \mathrm{HVs}$ underwent QST and an investigation of the functionality of diffuse noxious inhibitory controls (DNICs) by conditioned pain modulation (CPM). ${ }^{36}$ During these tests, pain was evaluated using an NPRS of 0 to 10 .

QST studies included thermal detection and thermal pain thresholds: cold detection thresholds (CDTs) and warm detection thresholds (WDTs) and cold pain thresholds (CPTs) and warm pain thresholds (WPTs). The advanced thermal stimulator (ATS) thermode $(30 \times 30 \mathrm{~mm}$; Medoc Ltd, Ramat Yishai, Israel) connected to the Pathway-Medoc (Medoc Ltd) is applied to the volar side of the patient's dominant forearm. From the baseline value of $32^{\circ} \mathrm{C}$, the Pathway-Medoc delivers an adjustable temperature peak (in cold and heat, depending on a regular slope of $1^{\circ} \mathrm{C}$ ) and is controlled by rapid feedback. This device is used to evaluate the detection (when the individual begins to feel the thermal change) and pain threshold (when the individual begins to feel pain) to heat and cold by calculating the mean of 3 measures.

CPM was performed as described in previous publications. $^{3,36}$ The ATS thermode is applied to the volar side of the dominant forearm. The Pathway-Medoc delivers stimulation at the predetermined pain thresholds for a period of 30 seconds and the subject rates her pain. The subject then puts the nondominant hand in a water bath at $46.5^{\circ} \mathrm{C}$ for a period of 60 seconds. After having dried her hand, the patient undergoes a similar sequence of stimuli lasting 30 seconds for pain evaluation. The aim of this test is to trigger the stimulation of pain descending pathways. If these pathways are functional, the second series of stimuli will be less painful than the first one because of the inhibitory effect on pain stimuli. It is the reverse if these pathways are not functional. ${ }^{36}$ The amplitude of the CPM is determined by calculating the difference between the NPRS scores before and after immersion of the hand: a diminution of pain after the stimulus accompanies a good functioning of the DNICs. 


\section{Statistical Methods}

Considering the number of subjects, it is estimated that $30 \%$ to $50 \%$ of patients with FM may have an SFN. ${ }^{14,37}$ Thus, a sample of 50 patients should provide a margin of error of $5 \%$ to $6 \%$ of the $95 \%$ confidence interval (CI) for the prevalence of SFN. This number would make it possible to demonstrate a difference in terms of SFN between 50 patients with FM and 50 HVs on the order of $30 \%$ (1\% vs. $30 \%)$ for a risk of error of first bilateral species of $5 \%$ and a power of $>90 \%$.

Statistical analysis was performed using STATA software (version 13; StataCorp, College Station, TX, U.S.A.) for a 2 -sided type I error at $5 \%$. Continuous data were described as mean \pm standard deviation or median [interquartile range] according to the statistical distribution. The assumption of normality was assessed using the Shapiro-Wilk test. ESC (on hands and feet) was first treated as a continuous parameter. ESC was then dichotomized according to the statistical distribution and to the clinical relevance. More precisely, a threshold was determined according to the first quartile, separating the $25 \%$ lowest values of ESC from the others. The comparisons concerning the primary endpoint (ESC value) were conducted using random-effects models, taking into account between-participant and withinparticipant variability (as random effects) and evaluating the following fixed effects: the group (FM/controls), the time $\left(T_{0} / T_{30}\right)$, and, when appropriate, the dominant side (yes/no, for hand). The interactions between covariates were studied. For the other comparisons (without repeated data for the same subject), Student's $t$ test or the Mann-Whitney test was applied to compare the FM and control groups for continuous outcomes, whereas the chi-squared test or Fisher's exact test was carried out for categorical variables. Finally, the relationships between the quantitative variables were studied using correlation coefficients (Pearson or Spearman, according to the statistical distribution). Šidák's type I error correction was applied to take into account the multiple comparisons. Results were significantly different if $P<0.05$.

\section{RESULTS}

\section{Baseline Characteristics}

Fifty right-handed female patients with FM and $50 \mathrm{HVs}$ were included and matched by age, gender, BMI, hand predominance, and menopausal status (Table 1). ACR criteria were positive for all patients with FM (Widespread Pain Index mean score of $11.8 \pm 3.5$; Symptom Severity Scale mean score of $5.9 \pm 1.5$ ). The FIRST mean score was $5.2 \pm 1.0$; the FIQ mean score was $56.3 \pm 17.4$. HVs were more professionally active than patients with FM $(P<0.01)$. The mean duration of FM was $12 \pm 3$ years. The mean NPRS score was $6.1 \pm 2.0$. BPI scores highlighted different types of pain and its impact on several domains: the mean score for the most severe pain was $7.5 \pm 1.6$, and that for the lowest pain was $3.6 \pm 1.9$; mean scores for the discomfort of pain on sleep and mood were $6.8 \pm 2.7$ and $5.3 \pm 2.7$, respectively.

\section{Electrochemical Conductance Values}

ESC values on feet and hands were not significantly different at $T_{0}$ and $T_{30}$. Hand ESC values differed significantly between patients with $\mathrm{FM}$ and $\mathrm{HVs}$ $(71.4 \pm 11.2 \mu \mathrm{S}$ vs. $74.4 \pm 10.3 \mu \mathrm{S}$, mean difference $-3.12 \mu \mathrm{S} ; 95 \%$ CI $[-5.18,-1.06] ; P=0.003)$. ESC values were lower on the dominant right hand (effect size 2.36 ; $95 \%$ CI $[0.297 ; 4.42] ; P=0.03)$. A lower conductance $(\mathrm{ESC}<66 \mu \mathrm{S})$ was observed in more patients with FM $(n=14 / 50,28 \%)$ than in HVs $(n=$ $6 / 50,12 \% ; P=0.046)$ on the dominant hand. No difference was observed on the feet between patients with FM and HVs.

\section{Psychological, Quality of Life, Sleep, and Social Characteristics}

All collected characteristics were impaired in patients with FM compared to HVs (Table 2). Patients with FM were more depressive (HADS depression scores

Table 1. Demographic Data of Patients With Fibromyalgia vs. Healthy Volunteers

\begin{tabular}{|c|c|c|c|}
\hline & $\begin{array}{l}\text { Patients } \\
(n=50)\end{array}$ & $\begin{array}{l}\text { Volunteers } \\
(n=50)\end{array}$ & $\begin{array}{l}P \\
\text { Value }\end{array}$ \\
\hline Age, years (mean $\pm S D$ ) & $51 \pm 9$ & $51 \pm 10$ & 0.84 \\
\hline $\mathrm{BMI}, \mathrm{kg} / \mathrm{m}^{2}($ mean $\pm \mathrm{SD})$ & $27.2 \pm 5.3$ & $26.8 \pm 4.8$ & 0.06 \\
\hline Currently employed, $n(\%)$ & $32(64)$ & $44(88)$ & 0.005 \\
\hline Hand performance & $\begin{array}{l}\text { All right- } \\
\text { handed }\end{array}$ & $\begin{array}{l}\text { All right- } \\
\text { handed }\end{array}$ & \\
\hline $\begin{array}{l}\text { Menopause/non-menopause } \\
\text { (n) }\end{array}$ & $26 / 24$ & $25 / 25$ & 0.89 \\
\hline Pain (mean NPRS score \pm SD) & $6.1 \pm 2.0$ & & \\
\hline $\begin{array}{l}\text { Duration of disease, years } \\
\text { (mean } \pm \text { SD) }\end{array}$ & $12 \pm 3$ & & \\
\hline
\end{tabular}

BMI, body mass index; NPRS, numerical pain rating scale; SD, standard deviation. 
$7.5 \pm 3.9$ vs. $2.9 \pm 2.9, P<0.001$; BDI global scores $9.3 \pm 5.2$ vs. $2.9 \pm 4.0, \quad P<0.001)$ and anxious (HADS anxiety scores $11.5 \pm 3.8$ vs. $6.3 \pm 3.0$, $P<0.001)$ than HV patients, respectively. The SF-12 physical composite score was lower in patients with $\mathrm{FM}$ than in HVs $(36.1 \pm 5.4$ vs. $48.0 \pm 3.5$, respectively; $P<0.001$; Table 3), reflecting an impaired quality of life. Sleep disorders were significantly more pronounced in patients with FM compared to HVs (PSQI global scores $11.4 \pm 4.4$ vs. $4.5 \pm 2.7$, respectively; $P<0.001$ ), and fatigue was more severe (FSS global scores $5.2 \pm 1.2$ vs. $2.4 \pm 1.2$, respectively; $P<0.001$ ). PCS global scores and subscores were higher for patients with FM $(25.3 \pm 10.8)$ than for HVs $(12.0 \pm 10.3$; $P<0.001)$. Patients with FM were more socially vulnerable than HVs (EPICES mean scores $38.2 \pm 17.3$ vs. $28.8 \pm 16.2$, respectively; $P<0.01$ ).

\section{Psychophysics Testing}

As shown in Figure 1, QST on the dominant side demonstrated that detection thresholds occurred at later temperatures and pain thresholds at earlier temperatures in patients with FM compared with HVs. CDTs were lower in patients with FM than in HVs $\left(29.9 \pm 0.7^{\circ} \mathrm{C}\right.$ vs. $31.0 \pm 0.6^{\circ} \mathrm{C}$, respectively; $P<0.001$ ), whereas WDT temperatures were higher in patients with FM than in HVs $\left(34.8 \pm 0.7^{\circ} \mathrm{C}\right.$ vs. $33.6 \pm 0.6^{\circ} \mathrm{C}$, respectively; $P<0.001)$. For pain thresholds, CPTs were at a higher temperature in patients with FM than in HVs $\left(24.7 \pm 2.0^{\circ} \mathrm{C} \quad\right.$ vs. $\quad 18.4 \pm 3.2^{\circ} \mathrm{C}, \quad$ respectively; $\mathrm{P}<0.001)$ and WPTs at a lower temperature in patients with FM than in $\mathrm{HVs}\left(40.1 \pm 2.8^{\circ} \mathrm{C}\right.$ vs. $43.0 \pm 3.9^{\circ} \mathrm{C}$, respectively; $P<0.001)$.

CPM testing showed that DNICs were not functional in patients with FM compared to HVs (NPRS delta: $-0.3 \pm 1.9$ vs. $-6.0 \pm 1.9$, respectively; $P=0.001$ ). Only 6 of 24 patients with FM displayed slightly functioning DNICs (diminution of $2 \pm 1$ on the NPRS), 19 patients had no change, and 8 patients were more facilitatory (increase of $2 \pm 1$ on the NPRS), while all HVs had functioning DNICs $(-5 \pm 1.5$ on the NPRS). No correlation was observed between ESC and CPM $(r=0.17, P=0.63)$ or with any measured parameter $(r$ ranging from -0.18 to +0.20 , and all with $P>0.05$ ), including severity of pain $(r=-0.12, P=0.40)$ and duration of disease $(r=-0.11, P=0.45)$.

\section{Concomitant Medication}

Patients with FM did not interrupt their usual medications during the study. In the FM group, 5 patients $(10 \%)$ had no treatment, 18 patients $(36 \%)$ took nonopioid analgesics, 17 patients (34\%) took weak opioid analgesics, 15 patients $(30 \%)$ took antidepressants, and 2 patients $(4 \%)$ took anticonvulsants. Forty patients with FM (80\%) received more than 2 drugs for chronic pain.

\section{DISCUSSION}

This pilot study shows for the first time that the sudomotor function on the hands of female patients with FM is significantly diminished compared to that of HVs and that the cursors of detection and pain are slightly changed in patients with FM. The difference between ESC values between the groups (71.4 \pm 11.2 $\mu \mathrm{S}$ for patients with FM vs. $74.4 \pm 10.3 \mu \mathrm{S}$ for HVs), although statistically significant, was small, and the clinical pertinence needs to be explored, especially with electromyography. Sudomotor function change may be indicative of SFN or may be isolated, since no gold standard for the diagnosis of SFN has been described so far. A degeneration of terminals of small nerve fibers often characterizes SFN and autonomic sweat gland dysfunction, but consequences have been studied more

Table 2. Psychological Characteristics of Patients With Fibromyalgia vs. Healthy Volunteers

\begin{tabular}{|c|c|c|c|}
\hline & Patients $(n=50)$ & Volunteers $(n=50)$ & $P$ Value \\
\hline HADS anxiety score (mean \pm SD) & $11.5 \pm 3.8$ & $6.3 \pm 3.0$ & $<0.001$ \\
\hline HADS anxiety score $>7, n(\%)$ & $46(92)$ & $15(30)$ & $<0.001$ \\
\hline HADS depression score (mean \pm SD) & $7.5 \pm 3.9$ & $2.9 \pm 2.9$ & $<0.001$ \\
\hline HADS depression score $>7, n(\%)$ & $24(48)$ & $2(4)$ & $<0.001$ \\
\hline BDI global score (mean \pm SD) & $9.3 \pm 5.2$ & $2.9 \pm 4.0$ & $<0.001$ \\
\hline PCS rumination score (mean $\pm S D$ ) & $8.4 \pm 3.8$ & $5.4 \pm 1.3$ & $<0.001$ \\
\hline PCS exaggeration score (mean \pm SD) & $4.6 \pm 2.8$ & $2.4 \pm 2.7$ & $<0.001$ \\
\hline PCS impuissance score (mean \pm SD) & $12.3 \pm 6.0$ & $4.2 \pm 4.1$ & $<0.001$ \\
\hline PCS global score (mean \pm SD) & $25.3 \pm 10.8$ & $12.0 \pm 10.3$ & $<0.001$ \\
\hline
\end{tabular}

BDI, Beck Depression Inventory; HADS, Hospital Anxiety and Depression Scale; PCS, Pain Catastrophizing Scale; SD, standard deviation 
Table 3. Quality of Life, Sleep, and Social Characteristics of Patients With Fibromyalgia vs. Healthy Volunteers

\begin{tabular}{lllc}
\hline & Patients $(n=50)$ & Volunteers $(n=50)$ & $P$ Value \\
\hline SF-12 physical composite score (mean \pm SD) & $36.1 \pm 5.4$ & $48.0 \pm 3.5$ & $<0.001$ \\
SF-12 mental composite score (mean \pm SD) & $41.1 \pm 6.7$ & $43.3 \pm 5.3$ & 0.07 \\
PSQI global score (mean \pm SD) & $11.4 \pm 4.4$ & $4.5 \pm 2.7$ & $<.001$ \\
FSS global score (mean \pm SD) & $5.2 \pm 1.2$ & $2.4 \pm 1.2$ & $<0.001$ \\
Precarity and health inequalities (EPICES) score (mean \pm SD) & $38.2 \pm 17.3$ & $28.8 \pm 16.2$ & 0.008 \\
Precarity and health inequalities (EPICES), $n$ (\%) & $28(56)$ & $16(32)$ & 0.02 \\
\hline
\end{tabular}

EPICES, Evaluation de la Précarité et des Inégalités de Santé dans les Centres d'Examens de Santé; FSS, Fatigue Severity Scale; PCS, Pain Catastrophizing Scale; PSQI, Pittsburgh Sleep Quality Index; SD, standard deviation; SF-12, 12-Item Short Form Survey.

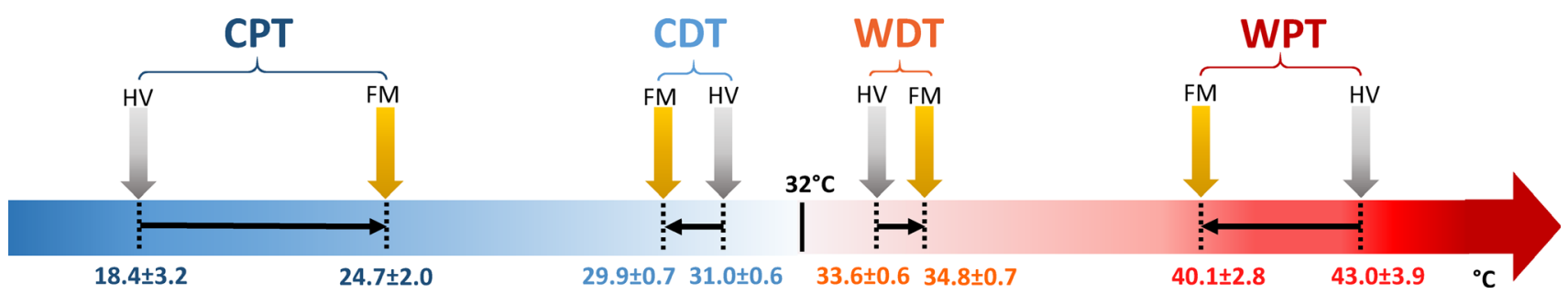

Figure 1. Cold and warm detection thresholds and cold and warm pain thresholds in patients with fibromyalgia and healthy volunteers. Blue and red colors represent cold and warm temperatures, respectively. CDT, cold detection thresholds; CPT, cold pain thresholds; FM, patients with fibromyalgia; HV, healthy volunteers; WDT, warm detection thresholds; WPT, warm pain thresholds.

in symmetry length-dependent neuropathies as in diabetes than in a diffuse pathology as in FM. It is interesting to note that ESC values are much lower in these studies than the values observed in our study, $<40 \mu \mathrm{S}$ indicating severe dysfunction and $>60 \mu \mathrm{S}$ indicating normal functioning. ${ }^{19,38-40}$ Lower ESC values have been shown to be significantly associated with increasing neuropathic symptoms, and patients with ESC values of $<40 \mu \mathrm{S}$ were more than 4 times as likely as patients with ESC values of $>40 \mu \mathrm{S}$ to have 2 or more abnormal cardiac autonomic neuropathy test outcomes. ${ }^{19}$ It has also been shown that FM is accompanied by autonomic dysfunction ${ }^{41}$ and displays high ESC reactivity to stress, suggesting unique psychophysiological features for this pathology, as described in the literature. ${ }^{42}$ Our study confirms the findings of publications that focused on $\mathrm{ESC}^{42}$ or $\mathrm{QST}^{43}$ alone and combined these 2 approaches.

In our study, QST yielded interesting information, confirming that thermal detection and pain thresholds are modified in FM. ${ }^{3,4,43}$ The interesting new additional finding is that the cursors of detection and pain are slightly changed in FM. First, a delayed thermal detection is observed in patients with FM compared to HVs for cold and hot stimuli, suggesting an impairment of superficial discriminative thermal receptors and/or fibers that convey temperature. Second, an earlier perception of painful stimuli suggests a specificity of acute noxious heat-sensing mediation in FM, as acute pain represents a crucial alarm signal to protect from injury. A-delta and $\mathrm{C}$ sensory nerve fibers that innervate the skin fire earlier, underlining the possibility of peripheral sensitization and receptor activation in FM. A recent study has shown the importance of a trio of TRP receptors (TRPM3, TRPV1, and TRPA1) that are functionally redundant TRP channels, representing a fault-tolerant mechanism to avoid burn injury. ${ }^{44}$ Little is known about these receptors in FM, but preclinical and clinical studies have shown that certain TRPV haplotypes contribute to the symptoms of FM. ${ }^{45,46}$ QST findings in FM reveal an alarm system to thermal insults that is amplified and prioritized compared to discriminative information. Although no correlation could be shown between QST and ESC, the impairment of ESC in FM reinforces the impaired transmission of thermal perception and of sweat gland function. As recommended, it would be necessary to complete our ESC and QST findings with questionnaires, like the Composite Autonomic Symptom Score-31 (COMPASS-31) ${ }^{47}$ and 1 additional test, like the quantitative sudomotor axon reflex test, which assesses the postganglionic sympathetic cholinergic sudomotor function in the extremities, or skin biopsy, ${ }^{7}$ so that a diagnosis of SFN could be proposed in our FM sample. $^{48}$

As described previously, ${ }^{36}$ DNICs are very poorly functioning in patients with FM, some patients even 
displaying facilitation of pain. This dysfunction of DNICs has been described as a cause or a consequence of the pathology. These pathways originate in the brainstem and periaqueductal gray matter and are involved in DNICs that are part of a central pain modulatory system relying on spinal and supraspinal mechanisms. Our data do not show any correlation between ESC values and the functionality of DNICs; this may suggest that modulation of the perception/autonomic system is left to rely on modulation at the periphery or upstream of the periaqueductal gray matter, via the insula and brain areas.

Another finding of our study is that ESC values in patients with FM were significantly diminished on the dominant hand, suggesting a nonsymmetrical severity of autonomic dysfunction, considering that no clinical sign or symptom of carpal tunnel syndrome was noted in the patients at inclusion. The insula is well known to encode both the intensity and the laterality ${ }^{49,50}$ of painful and nonpainful thermal stimuli. A lateralization in autonomic dysfunction has also been shown in pathological conditions like ischemic stroke and is usually contralateral. The same lateralization of autonomic function with opposite effects on sympathovagal balance has been reported in the literature, suggesting that, beyond the controlling network, the cortical modulation of the autonomic nervous system is asymmetric. ${ }^{51}$ The insular cortex plays a crucial role in the central autonomic network, as hemispheric lateralization in autonomic activity is mediated by the right-sided insular cortex. ${ }^{52}$ The altered resting state connectivity between the insula and other brain regions known to participate in pain perception/modulation may be associated with the experience of chronic pain in patients with $\mathrm{FM}^{53}$ Likewise, somatosensory S1 functional connectivity is altered by sustained pain and associated with clinical/ autonomic dysfunction in patients with $\mathrm{FM}^{5}{ }^{54}$ These observations lead us to suggest that ESC values observed in the hands might have a central component in several brain regions. A larger alteration on the dominant side (right in the study) has not been described so far in the literature but may be a consequence of a globally lateralized impairment in FM, as patients had no signs or symptoms of any carpal tunnel syndrome or other distal abnormality.

This study also underlines how FM affects all parameters of psychological, quality of life, sleep, and social domains and makes these patients particularly vulnerable in everyday life. However, no correlation of psychophysics results could be shown with any parameters, including duration of disease, anxio-depressive state, or other comorbidities.

A few limitations exist in this study; namely, concomitant skin biopsy could have yielded additional information on the presence of SFN, and the fact that less than a third of patients had a modified skin conduction. QST is a good instrument to evaluate small fiber functionality, but it has a subjective component. A larger number of patients with a subtyping of patients with FM could also be an interesting development for future studies.

\section{CONCLUSION}

Collective data obtained in this study show that the sudomotor function measured by ESC in patients with FM is significantly diminished on the dominant hand. This impairment parallels the changes of thermal detection and pain thresholds in the context of absent spinal pain modulation by DNICs. It appears then as a local peripheral phenomenon with a lateralization on the dominant side of the body and/or a central modulation of the autonomic system at hemispheric or insula levels bypassing the DNICs. ESC values combined with QST values are relevant in the context of patients with FM and need to be explored further in this complex nociception-autonomic system intertwining.

\section{ACKNOWLEDGEMENTS}

We thank the patients and volunteers for their participation; the team of the Clinical Pharmacology Department, Clermont-Ferrand, France, for their technical help in the realization of this study; and the University Hospital of Clermont-Ferrand for their financial support.

\section{CONFLICTS OF INTEREST}

The authors have no conflicts of interest to declare.

\section{REFERENCES}

1. Häuser W, Fitzcharles M-A. Facts and myths pertaining to fibromyalgia. Dialogues Clin Neurosci. 2018;20:53-62.

2. Häuser W, Ablin J, Fitzcharles M-A, et al. Fibromyalgia. Nat Rev Dis Primers. 2015;1:1-22.

3. Pickering G, Pereira B, Dufour E, Soule S, Dubray C. Impaired modulation of pain in patients with postherpetic neuralgia. Pain Res Manag. 2014;19:e19-e23.

4. Julien N, Goffaux P, Arsenault P, Marchand S. Widespread pain in fibromyalgia is related to a deficit of endogenous pain inhibition. Pain. 2005;114:295-302. 
5. Caro XJ, Winter EF. Evidence of abnormal epidermal nerve fiber density in fibromyalgia: clinical and immunologic implications. Arthritis Rheumatol. 2014;66:1945-1954.

6. Doppler K, Rittner HL, Deckart M, Sommer C. Reduced dermal nerve fiber diameter in skin biopsies of patients with fibromyalgia. Pain. 2015;156:2319-2325.

7. Terkelsen AJ, Karlsson P, Lauria G, Freeman R, Finnerup NB, Jensen TS. The diagnostic challenge of small fibre neuropathy: clinical presentations, evaluations, and causes. Lancet Neurol. 2017;16:934-944.

8. Ramírez M, Martínez-Martínez L-A, Hernández-Quintela E, Velazco-Casapía J, Vargas A, Martínez-Lavín M. Small fiber neuropathy in women with fibromyalgia. An in vivo assessment using corneal confocal bio-microscopy. Semin Arthritis Rheum. 2015;45:214-219.

9. Levine TD, Saperstein DS. Routine use of punch biopsy to diagnose small fiber neuropathy in fibromyalgia patients. Clin Rheumatol. 2015;34:413-417.

10. Thaisetthawatkul P, Fernandes Filho JA, Herrmann DN. Autonomic evaluation is independent of somatic evaluation for small fiber neuropathy. J Neurol Sci. 2014;344:5154.

11. Kulshreshtha P, Deepak KK. Autonomic nervous system profile in fibromyalgia patients and its modulation by exercise: a mini review. Clin Physiol Funct Imaging. 2013;33:83-91.

12. Martínez-Martínez L-A, Mora T, Vargas A, FuentesIniestra M, Martínez-Lavín M. Sympathetic nervous system dysfunction in fibromyalgia, chronic fatigue syndrome, irritable bowel syndrome, and interstitial cystitis: a review of casecontrol studies. J Clin Rheumatol. 2014;20:146-150.

13. Lodahl M, Treister R, Oaklander AL. Specific symptoms may discriminate between fibromyalgia patients with vs without objective test evidence of small-fiber polyneuropathy. Pain Rep. 2018;3:e633.

14. Oaklander AL, Herzog ZD, Downs HM, Klein MM. Objective evidence that small-fiber polyneuropathy underlies some illnesses currently labeled as fibromyalgia. Pain. 2013;154:2310-2316.

15. Lefaucheur J-P, Wahab A, Planté-Bordeneuve V, et al. Diagnosis of small fiber neuropathy: a comparative study of five neurophysiological tests. Neurophysiol Clin. 2015;45:445-455.

16. Mao F, Liu S, Qiao X, et al. Sudoscan is an effective screening method for asymptomatic diabetic neuropathy in Chinese type 2 diabetes mellitus patients. J Diabetes Investig. 2017;8:363-368.

17. Fealey RD, Low PA, Thomas JE. Thermoregulatory sweating abnormalities in diabetes mellitus. Mayo Clin Proc. 1989;64:617-628.

18. Selvarajah D, Cash T, Davies J, et al. SUDOSCAN: a simple, rapid, and objective method with potential for screening for diabetic peripheral neuropathy. PLoS One. 2015;10: e0138224.

19. Casellini CM, Parson HK, Richardson MS, Nevoret ML, Vinik AI. Sudoscan, a noninvasive tool for detecting diabetic small fiber neuropathy and autonomic dysfunction. Diabetes Technol Ther. 2013;15:948-953.

20. Castro J, Miranda B, Castro I, de Carvalho M, Conceição I. The diagnostic accuracy of Sudoscan in transthyretin familial amyloid polyneuropathy. Clin Neurophysiol. 2016;127:2222-2227.

21. Sahuc P, Chiche L, Dussol B, Pouget J, Franques J. Sudoscan as a noninvasive tool to assess sudomotor dysfunction in patients with Fabry disease: results from a case-control study. Ther Clin Risk Manag. 2016;12:135-138.

22. Mao F, Liu S, Qiao X, et al. SUDOSCAN, an effective tool for screening chronic kidney disease in patients with type 2 diabetes. Exp Ther Med. 2017;14:1343-1350.

23. Bordier L, Dolz M, Monteiro L, Névoret M-L, Calvet $\mathrm{J}-\mathrm{H}$, Bauduceau B. Accuracy of a rapid and non-invasive method for the assessment of small fiber neuropathy based on measurement of electrochemical skin conductances. Front Endocrinol (Lausanne). 2016;7:1-6.

24. Wolfe F, Clauw DJ, Fitzcharles M-A, et al. 2016 Revisions to the 2010/2011 fibromyalgia diagnostic criteria. Semin Arthritis Rheum. 2016;46:319-329.

25. Bennett R. The Fibromyalgia Impact Questionnaire (FIQ): a review of its development, current version, operating characteristics and uses. Clin Exp Rheumatol. 2005;23(5 Suppl 39):S154-S162.

26. Perrot S, Bouhassira D, Fermanian J. Cercle d'Etude de la Douleur en Rhumatologie. Development and validation of the Fibromyalgia Rapid Screening Tool (FiRST). Pain. 2010;150:250-256.

27. Cleeland CS, Ryan KM. Pain assessment: global use of the Brief Pain Inventory. Ann Acad Med Singapore. 1994;23:129-138.

28. Gandek B, Ware JE, Aaronson NK, et al. Crossvalidation of item selection and scoring for the SF-12 health survey in nine countries: results from the IQOLA project. $J$ Clin Epidemiol. 1998;51:1171-1178.

29. Ware JE, Sherbourne CD. The MOS 36-item shortform health survey (SF-36). I. Conceptual framework and item selection. Med Care. 1992;30:473-483.

30. Zigmond AS, Snaith RP. The hospital anxiety and depression scale. Acta Psychiatr Scand. 1983;67:361370 .

31. Beck AT, Ward CH, Mendelson M, Mock J, Erbaugh J. An inventory for measuring depression. Arch Gen Psychiatry. 1961;4:561-571.

32. Buysse DJ, Reynolds CF, Monk TH, Berman SR, Kupfer DJ. The Pittsburgh Sleep Quality Index: a new instrument for psychiatric practice and research. Psychiatry Res. 1989;28:193-213.

33. Krupp LB, LaRocca NG, Muir-Nash J, Steinberg AD. The fatigue severity scale. Application to patients with multiple sclerosis and systemic lupus erythematosus. Arch Neurol. 1989;46:1121-1123.

34. Sullivan MJL, Bishop SR, Pivik J. The Pain Catastrophizing Scale: development and validation. Psychol Assess. 1995; 7:524-532. 
35. Labbe E, Blanquet M, Gerbaud L, et al. A new reliable index to measure individual deprivation: the EPICES score. Eur J Public Health. 2015;25:604-609.

36. Pickering G, Macian N, Delage N, et al. Milnacipran poorly modulates pain in patients suffering from fibromyalgia: a randomized double-blind controlled study. Drug Des Devel Ther. 2018;12:2485-2496.

37. Mayaudon H, Miloche P-O, Bauduceau B. A new simple method for assessing sudomotor function: relevance in type 2 diabetes. Diabetes Metab. 2010;36(6 Pt 1):450-454.

38. Üçeyler N, Zeller D, Kahn A-K, et al. Small fibre pathology in patients with fibromyalgia syndrome. Brain. 2013;136:1857-1867.

39. Hubert D, Brunswick P, Calvet J-H, Dusser D, Fajac I. Abnormal electrochemical skin conductance in cystic fibrosis. $J$ Cyst Fibros. 2011;10:15-20.

40. Freedman BI, Bowden DW, Smith SC, Xu J, Divers J. Relationships between electrochemical skin conductance and kidney disease in type 2 diabetes. J Diabetes Complications. 2014;28:56-60.

41. da Cunha Ribeiro R, Roschel H, Artioli G, et al. Cardiac autonomic impairment and chronotropic incompetence in fibromyalgia. Arthritis Res Ther. 2011;13:R190.

42. Thieme K, Rose U, Pinkpank T, Spies C, Turk DC, Flor H. Psychophysiological responses in patients with fibromyalgia syndrome. J Psychosom Res. 2006;61:671-679.

43. Hurtig IM, Raak RI, Kendall SA, Gerdle B, Wahren LK. Quantitative sensory testing in fibromyalgia patients and in healthy subjects: identification of subgroups. Clin J Pain. 2001;17:316-322.

44. Vandewauw I, De Clercq K, Mulier M, et al. A TRP channel trio mediates acute noxious heat sensing. Nature. 2018;555:662-666.

45. Park D-J, Kim S-H, Nah S-S, et al. Polymorphisms of the TRPV2 and TRPV3 genes associated with fibromyalgia in a
Korean population. Rheumatology (Oxford). 2016;55:15181527.

46. Chen W-N, Lee C-H, Lin S-H, et al. Roles of ASIC3, TRPV1, and NaV1.8 in the transition from acute to chronic pain in a mouse model of fibromyalgia. Mol Pain. 2014;10:40.

47. Treister R, O’Neil K, Downs HM, Oaklander AL. Validation of the composite autonomic symptom scale 31 (COMPASS-31) in patients with and without small fiber polyneuropathy. Eur J Neurol. 2015;22:1124-1130.

48. Thaisetthawatkul P, Fernandes Filho JAM, Herrmann DN. Contribution of QSART to the diagnosis of small fiber neuropathy. Muscle Nerve. 2013;48:883-888.

49. Brooks JCW, Nurmikko TJ, Bimson WE, Singh KD, Roberts N. fMRI of thermal pain: effects of stimulus laterality and attention. NeuroImage. 2002;15:293-301.

50. Cortelli P, Giannini G, Favoni V, Cevoli S, Pierangeli G. Nociception and autonomic nervous system. Neurol Sci. 2013;34(Suppl 1):S41-S46.

51. Constantinescu V, Detante O, Matei D, et al. Cortical lateralization and cardiac autonomic control. Insights from insular stroke and epilepsy. Arch Clin Cases. 2017; 4:154-168.

52. Meyer S, Strittmatter M, Fischer C, Georg T, Schmitz B. Lateralization in autonomic dysfunction in ischemic stroke involving the insular cortex. NeuroReport. 2004; 15:357-361.

53. Ichesco E, Schmidt-Wilcke T, Bhavsar R, et al. Altered resting state connectivity of the insular cortex in individuals with fibromyalgia. J Pain. 2014;15:815-826.e1.

54. Kim J, Loggia ML, Cahalan CM, et al. The somatosensory link in fibromyalgia: functional connectivity of the primary somatosensory cortex is altered by sustained pain and is associated with clinical/autonomic dysfunction. Arthritis Rheumatol. 2015;67:1395-1405. 